[24] Nagayasu, T., Yamasaki, N., Tsuchiya, T., Matsumoto, K., Miyazaki, T., Hatachi, G. et. al. (2015). The evolution of bronchoplasty and broncho-angioplasty as treatments for lung cancer: evaluation of 30 years of data from a single institution. European Journal of Cardio-Thoracic Surgery, 49 (1), 300-306. doi: http://doi.org/10.1093/ejcts/ezv065

[25] Maurizi, G., Ibrahim, M., Andreetti, C., D’Andrilli, A., Ciccone, A. M., Pomes, L. M. et. al. (2014). Long-term results after resection of bronchial carcinoid tumour: evaluation of survival and prognostic factors. Interactive CardioVascular and Thoracic Surgery, 19 (2), 239-244. doi: http://doi.org/10.1093/icvts/ivu109

\title{
UTERINE FIBROIDS IMPACT ON FERTILITY AND PREGNANCY OUTCOME
}

\author{
Olena Doroha ${ }^{2}$ \\ Department of Obstetrics, Gynecology And Perinatology \\ Ukrainian State Institute of Reproductology ${ }^{1}$ \\ ztrololoz@i.ua \\ Mykola Iarotskyi \\ Medical director \\ Academic Medical Center \\ 5/14 Rohnedynska Str., Kyiv, Ukraine, 01004 \\ info@amcenter.com.ua \\ Iryna Iarotska \\ Department of Obstetrics, Gynecology and Perinatology ${ }^{1}$ \\ ir-nik@ukr.net \\ Liudmyla Semeniuk \\ Department of Reproductive Medicine and Surgery \\ Ukrainian Scientific and Practical Center for Endocrine Surgery, Transportation Endocrine \\ Organ and Tissues Ministry of Health of Ukraine \\ 13 A Klovsky Uzviz, Kyiv, Ukraine, 01021 \\ Semeniukliudmyla1@gmail.com \\ Olga Nikitina \\ ztrololoz@i.ua \\ ${ }^{1}$ Shupyk National Medical Academy of Postgraduate Education \\ 9 Dorohozhytska str., Kyiv, Ukraine, 04112 \\ ${ }^{2}$ State Scientific Institution "Scientific and Practical Center for Preventive and Clinical Medi- \\ cine" of the State Administration of Affairs \\ 5 Verkhnya str., Kyiv, Ukraine, 01014
}

\section{Abstract}

The clinical confirmation of the relationship between uterine leiomyoma and female infertility is of interest to scholars.

The aim of our research was to study obstetric history and the level of sex hormones in women of reproductive age with leiomyoma.

Materials and methods. The main group consisted of 90 women of reproductive age with uterine leiomyoma, the control group - 45 healthy women. Gynaecological and obstetric history, hormone content in peripheral blood and pelvic vessels (estradiol, progesterone) were analysed. Statistical processing of clinical material was performed using Microsoft Excel, Statistica 7.0, and Statistica 8.0 for Windows. 
Results. The frequency of infertility in the surveyed women with LM was $18.9 \%$. One in three patients in the main group (33.3\%) did not give birth, which was statistically different from the healthy women group. In this case, $25.6 \%$ of women in the main group did not use any methods of contraception. It was found that $51.11 \%$ of patients with LM had threatened miscarriage in their history, $37.5 \%$ - complicated delivery. Pathological changes in the concentrations of estradiol and progesterone in the preferential blood and blood vessels of women with fibroids have been identified. We have found that the content of sex hormones in the local bloodstream has a reliable relationship with the location of the myomatous node.

Conclusion. The obtained results may indicate that leiomyoma contributes to the reduction of fertility. This is evidenced by the fact that women with LM are more likely to have the risk of miscarriage, complicated delivery and delivery by caesarean section, including complicated one. The findings have made a significant contribution to the further development of effective strategies for the prevention and treatment of infertility in women with fibrotic uterine lesions.

Keywords: infertility, uterine fibroids, estrogen, progesterone, reproductive age, women.

DOI: $10.21303 / 2504-5679.2020 .001205$

\section{Introduction}

Uterine leiomyoma (fibroids, fibroma) is a tumour of smooth muscle cells, which is the most common gynaecologic oncologic benign disease among women of reproductive age $[1,2]$. This pathology is often identified in the diagnostic search in infertile couples $[3,4]$. Fibroids are hormone-dependent tumours and it has been proven that estrogens contribute to their growth: local estrogen concentrations at myomatic nodes are higher than in surrounding myometrium, possibly due to a higher aromatase concentration $[5,6]$. In this case, hormonal sensitivity is found more in the submucosal than subserous fibroids [7]. The submucosal form of the pathology discussed adversely affects the rate of implantation, the clinical course of pregnancy, its duration and outcome [1]. Fibroids can cause infertility through obstruction of the fallopian tubes, impaired migration of sperm and gamete transport, implantation of blastocysts through venous ectasia and endometrial atrophy near myoma, as well as increased expression of angiogenetic factors $[4,5]$.

The clinical confirmation of the relationship between leiomyoma and female infertility is of interest to scholars. Therefore, the aim of our research was to study obstetric history and the level of sex hormones in women of reproductive age with leiomyoma.

\section{Materials and methods}

At the Centre for Minimally Invasive Surgery of the State Scientific Institution "Scientific and Practical Centre for Preventive and Clinical Medicine" of the Government Department for Management of Affairs and the Academic Medical Centre 135 women of reproductive age were surveyed during October 2014 - November 2019. The studies were conducted solely with the written consent of participating women. The written consent to participate in the research described in detail all the foreseeable health risks and the techniques used in our study. A retrospective and prospective analysis of the case histories of 90 patients (mean age $31.2 \pm 1.4$ years) of patients with leiomyoma at different periods of pregnancy before and after organ-saving surgery from 0 to 5 years was conducted, which subsequently constituted the main study group - I. Exclusion criteria were age of patients over 36 years, disease duration over 5 years, diffuse variant of uterine leiomyoma, severe endocrine and autoimmune diseases, type II submucosal nodes. The control group consisted of 45 healthy women (mean age $32.7 \pm 1.9$ years). The analysis of family, somatic, gynaecological and obstetric history with detailed study of socio-economic status and working conditions of patients, general somatic examination, bimanual gynaecological examination, examination of the uterine cervix in the speculum, colposcopic examination data, the content of hormones in the peripheral blood and pelvic vessels (estradiol, progesterone) was conducted. Serum hormone content was determined before and after surgery, as well as during surgery applying radioimmunoassay technique using standard kits of reagents produced by Immunotech (Czech Republic). Surgical intervention in patients of the reproductive age of the main group was performed in the form of hysteroscopic examination applying the standard technique.

The study was based on the ethical principles of scientific research with the inclusion of people (Helsinki Declaration) and the provisions of the recommendations of GCP (good clinical 
practice). The study design was approved by the Centre for Minimally Invasive Surgery of the State Scientific Institution's Ethics Commission "Scientific and Practical Centre for Preventive and Clinical Medicine" of the Government Department for Management of Affairs and the Academic Medical Centre (protocol No. 24, 17.09.2014).

Statistical processing of clinical material was performed using Microsoft Excel, Statistica 7.0, and Statistica 8.0 for Windows. The sample parameters given in the tables were denoted as follows: $\mathrm{M}$ is the mean, $\mathrm{n}$ is the size of the analysed subgroup, $\mathrm{p}$ is the obtained significance level. The critical significance level was assumed to be $<0.05$ according to $\chi$ criteria.

\section{Results}

In our cohort of surveyed women with leiomyomas $(n=90)$, the incidence of infertility was $18.9 \%(n=17)$. One in three patients in the main group (33.3\%) did not give birth, which was statistically different from the healthy women group $(16.65 \%, \mathrm{p}=0.0002)$. At the same time, $25.6 \%$ of women in the main group did not use any methods of contraception.

The analysis of contraceptive methods allowed revealing a slightly higher rate of the use of intrauterine devices $24.5 \%(n=22)$ and lower rate of the use of barrier methods $10.0 \%(n=9)$ in women with LM relative to healthy control group women (Fig. 1). In the course of the study it was found that among the surveyed contingent there was a low level of oral contraceptive use $13.33 \%(n=12)$ in Group I compared to control group $30.0 \%(n=30)$, which can inhibit the development of fibroids (Fig. 1). It is noted that only women with the discussed pathology used the hormone-releasing intrauterine system - Mirena.

In the course of the study of obstetric history in women, with the presence of fibroids, there was a higher proportion of women who had a history of complicated childbirth (37.5\%), caesarean section (45.3\%) against the indicators of the control group (3.3\% and $17.4 \%$, respectively, $\mathrm{p}=0.017)$. At the same time, in Group 1 there was a higher percentage of caesarean sections with complications in 3 cases (4.7\%), and in CG such cases did not occur (Table 1). There were 46 (51.11\%) women of Group I, compared to 6 (26.1\%) women of CG, who had interruptions of pregnancy in their medical history. As regards abortions in medical history, in Group I the number of women who had abortions $49(54.4 \%)$ was significantly higher than in the control group $-8(26.6 \%)$. At the same time, in Group I there was a more specific proportion of women who had two abortions - 15 (30.6\%) cases, versus $2(25 \%)$ in CG. The proportion of patients with three abortions in medical history significantly prevailed in Group I - 9 (18.4 \%) women (Table 1). No such women were found in CG.

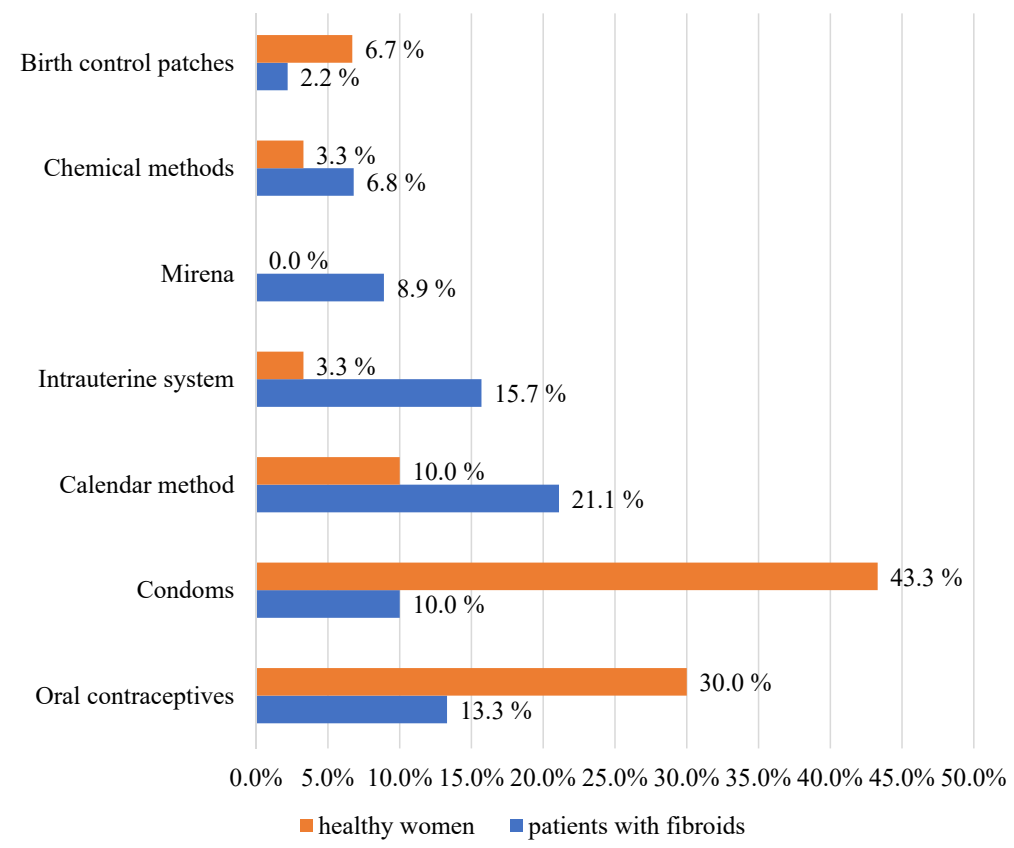

Fig. 1. Distribution (\%) of women of reproductive age surveyed by the method of contraception 
Table 1

Characteristics of reproductive function in surveyed women

\begin{tabular}{|c|c|c|c|c|c|}
\hline \multirow[t]{2}{*}{ Deliveries } & \multicolumn{2}{|c|}{$\begin{array}{c}\text { Group I } \\
\text { (women with fibroids) } \\
\mathrm{n}=90\end{array}$} & \multicolumn{2}{|c|}{$\begin{array}{c}\text { Control group } \\
\text { (healthy women) } \\
\mathbf{n = 3 0}\end{array}$} & \multirow{2}{*}{$\begin{array}{l}\chi \\
\mathbf{p}\end{array}$} \\
\hline & abs. & $\%$ & abs. & $\%$ & \\
\hline 0 & 30 & 33.3 & 5 & 16.6 & \\
\hline 1 & 51 & 56.6 & 14 & 46.6 & 19.1 \\
\hline 2 & 4 & 4.4 & 10 & 33.3 & 0.0002 \\
\hline 3 and more & 5 & 5.5 & 1 & 3.3 & \\
\hline Course of delivery & \multicolumn{2}{|c|}{$(n=74)$} & \multicolumn{2}{|c|}{$(n=23)$} & \multirow{5}{*}{$\begin{array}{c}5.6 \\
0.017\end{array}$} \\
\hline Physiological delivery & 45 & 54.7 & 19 & 32.6 & \\
\hline including complicated & 24 & 37.5 & 3 & 13.0 & \\
\hline Caesarean section & 19 & 45.3 & 4 & 17.4 & \\
\hline including complicated case & 3 & 4.7 & 0 & 0 & \\
\hline Threatened miscarriage & 46 & 51.11 & 6 & 26.1 & $\begin{array}{c}5.0 \\
0.025\end{array}$ \\
\hline Abortions in medical history, including & 49 & 54.4 & 8 & 26.6 & $\begin{array}{c}4.4 \\
0.034\end{array}$ \\
\hline 1 & 25 & 51.0 & 6 & 75.0 & \multirow{3}{*}{$\begin{array}{c}1.1 \\
0.576\end{array}$} \\
\hline 2 & 15 & 30.6 & 2 & 25.0 & \\
\hline 3 and more & 9 & 18.4 & 0 & 0 & \\
\hline
\end{tabular}

In women with the pathology under discussion, estradiol levels in the blood tended to increase continuously throughout the menstrual cycle. On day 5-7, its level exceeded the level of estradiol in women of CG almost twice (Fig. 2). However, on day 12-14 of the cycle, its secretion level was almost 1.5 times lower $(0.49 \pm 0.3 \mathrm{nmol} / \mathrm{ml})$ than the estradiol secretion level in the control group $(0.62 \pm 0.03 \mathrm{nmol} / \mathrm{ml})$. On day $21-24$, its level was almost no different from that of healthy women (Fig. 2).

$\mathrm{m}$

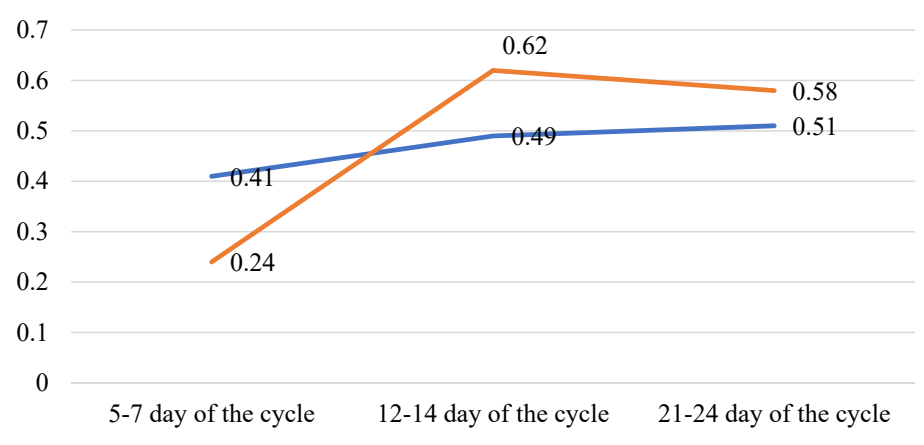

-women with fibroids healthy women

Fig. 2. The level of estradiol $(\mathrm{nmol} / \mathrm{ml})$ in the preferential blood of the women of both groups

The level of progesterone in women with fibroids on day 5-7 of the menstrual cycle was higher compared to the CG values $-3.72 \pm 0.02 \mathrm{nmol} / \mathrm{ml}$ against $2.11 \pm 0.77 \mathrm{nmol} / \mathrm{ml}$ (Fig. 3). On day $12-14$ of the cycle, its level increased to $6.08 \pm 0.43 \mathrm{nmol} / \mathrm{ml}$ in contrast to the control group. On day 21-24 of the menstrual cycle, the ratio of progesterone levels in Group I and CG differed almost twice (Fig. 3).

We have found that the content of sex hormones in the local bloodstream has a reliable relationship with the location of the myomatous node. According to our data, hyperostrogenemia was observed in the local bloodstream in the area of the uterine fundus against the background of 
progesterone content, which corresponds to the peripheral indicators of control (Table 2). In addition to the above, local progesteronemia was observed in the anterior and posterior uterine walls.

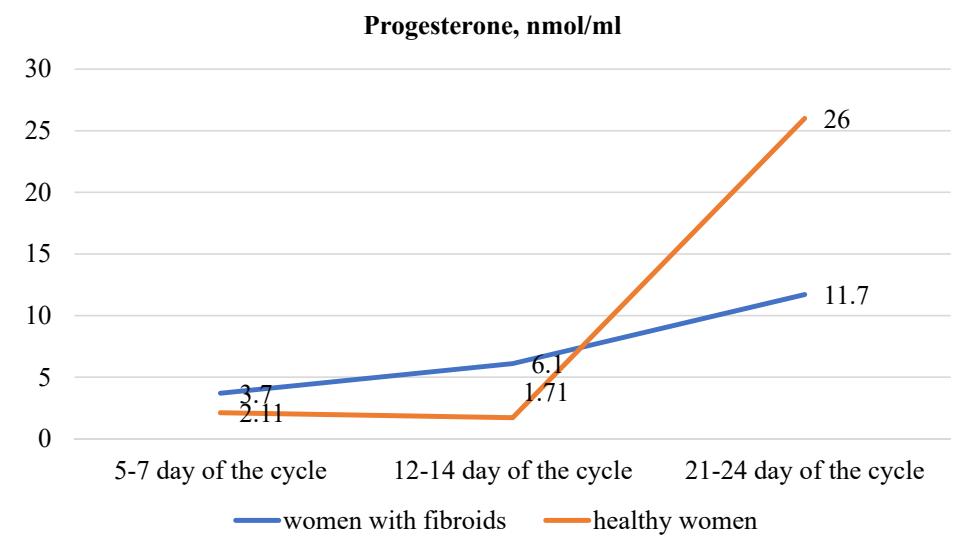

Fig. 3. Progesterone level $(\mathrm{nmol} / \mathrm{ml})$ in the preferential blood of the women in both groups

Table 2

Indicators of local hormonal homeostasis in surveyed women of reproductive age (M)

\begin{tabular}{cccccc}
\hline \multirow{2}{*}{$\begin{array}{c}\text { Indicators of } \\
\text { local blood flow }\end{array}$} & \multicolumn{2}{c}{$\begin{array}{c}\text { Localization of blood sampling during myomectomy } \\
\text { Groups }\end{array}$} & \multicolumn{2}{c}{$\begin{array}{c}\text { Peripheral blood flow } \\
\text { indicators }\end{array}$} \\
\cline { 2 - 6 } & Uterine fundus & Anterior and posterior uterine walls & Isthmus of uterus & main & control \\
\hline $\mathrm{E}_{2} \mathrm{nmol} / 1$ & $0.7100 .026^{*, * *}$ & $0.3450 .023^{*}$ & $0.2980 .005^{* * * *}$ & 0.5340 .023 & 0.3100 .026 \\
$\mathrm{P} \mathrm{nmol} / 1$ & $4.600 .08^{* *}$ & $9.630 .05^{* * * *}$ & $4.140 .03^{* * *}$ & 4.630 .05 & 2.00 .08
\end{tabular}

Note: statistically significant difference $(p<0.05): *$ - between local indicators and peripheral ones in the main group; ** - between local indicators of the main group and peripheral ones of the control group; $E_{2}$ - estrogen; $P$-progesterone.

\section{Discussion}

The literature data on the incidence of leiomyoma among infertile women are controversial. According to Dueholm M et al. [7], from $5 \%$ to $10 \%$ of infertile women have 1 or more fibroids. However, when all other causes of infertility are ruled out, fibroids are found only in 1-2\% of women [8]. Both infertility and age are associated with fibroids and can therefore confuse doctors trying to clarify the link between fibroids and infertility [9]. No studies have been conducted to date to indicate a direct cause-and-effect relationship between fibroids and infertility. In our cohort of surveyed women with leiomyomas, the incidence of infertility was $18.9 \%$.

Many hypotheses have been created to explain how fibroids can cause infertility. Studies of the blood supply to the vessels of uterus have shown that blood flow to the uterine fibroids is less than to the adjacent myometrium [1]. Endometrial inflammation and changed local hormonal environment, which was clinically proven in our study, may interfere with embryo implantation. Women with LM were characterized by the absence of ovulatory peak in the analysis of hormone secretion in the dynamics of the menstrual cycle, unlike CG healthy women. The level of progesterone tended to increase, but in the phase of the maximum hormonal activity of the yellow body, its level was insufficient for an adequate luteal phase. Relative hyperostrogeny was observed, which was not balanced by adequate progesterone interaction, which could impede the normal course of ovulation, prolonged endometrial proliferation phase, and impaired its complete secretory transformation. Thus, the dynamics of continuous synchronous growth of estradiol and progesterone throughout the menstrual cycle were traced, which made it impossible for them to have a dominant effect for the formation of a full two-phase menstrual cycle. It is proved that the LM on the background of almost normal concentrations of hormones in the general bloodstream is characterized by significant disturbances of local hormonal homeostasis in the form of relative hyperostrogeny against the background of a decrease in the concentration of progesterone, local hyperprolactinemia, and an increase in the content of somatomedin both in 
the arterial and in the venous vessels of the uterus $[10,11]$. This is confirmed by our findings that the content of sex hormones in the local bloodstream has a reliable relationship with the location of the myomatous node.

The ability of myoma to change uterine contractility is described, which may interfere with the interaction of sperm and ova or embryo migration [1, 12]. Large intramural fibroids interfere with the growth of the pregnant uterus and lead to asymmetric deformations with an increase in the contractility of healthy muscles [13]. In our cohort of patients, intramural fibroids and their location were most often on the anterior and posterior walls, and sometimes in the fundus in $22 \%$ of the surveyed. Intramuscular fibroids can limit the success of in vitro fertilization [4]. During pregnancy, a partially significant increase in growth is observed in about $25 \%$ of myomas, especially in the first trimester [4]. Pregnancy complications include early and late miscarriages, premature birth and rupture of the fetal membranes, chorio/endometritis, placental abruption, and postpartum haemorrhage/atony $[13,14]$.

Several authors have found that fibroids, regardless of their location, significantly reduce both implantation and clinical pregnancy $[15,16]$. The result of pregnancy is associated with the location of fibroids [17, 18]. Subserous fibroma does not affect fertility; all systemic reviews and meta-analyses agreed on this. However, Pritts E.A. et al. [9] proved the negative effect of submucosal fibroids (fibroids with endometrial lesions) on implantation rate, clinical course of pregnancy, and cases of miscarriages. In our cohort of patients with myomas, cases of threatened miscarriage, complicated delivery and delivery by caesarean section, including complications in comparison with the data of healthy women, are more often recorded in the in medical history. In this case, $67 \%$ of the surveyed had subserous localization of nodes.

De Vivo et al. [19] found that $71.4 \%$ of myomas increased during the first and second trimesters, while $66.6 \%$ increased between the second and third trimesters, which significantly increased the number of pregnancy complications. During pregnancy, myomas can grow rapidly, causing severe pain. However, Laughlin S et al. [20] documented fibrosis regression after childbirth in $72 \%$ of women, with a $50 \%$ decrease in fibroid volume between gestational onset and 3-6 months after delivery. Women who underwent miscarriage or adminestered progestins after childbirth underwent less regression of fibroids, but this difference was not found in women who underwent caesarean section, used other hormonal contraceptives, or breast-fed [20]. We found a somewhat low level (13.33\%) of oral contraceptive use in patients with leiomyomas. However, a slightly higher rate of the use of intrauterine devices in women with fibroids relative to healthy control group women may indicate that prolonged use of intrauterine contraceptives may play a large role in the emergence of LM in women of fertile age. The high proportion of women who did not use barrier means and did not use contraception at all among women in Group I may be a factor of risk of increasing the incidence of unwanted pregnancies and artificial abortions, which may contribute to the development of uterine tumours.

Study limitations. In our study, infertility level after leyomioma's surgical treatment was not evaluated.

Perspective of further research. To investigate woman fertility level after leyomioma's surgical treatment.

\section{Conclusion}

The obtained results may indicate that leiomyoma contributes to the reduction of fertility. This is evidenced by the fact that women with LM are more likely to have the risk of miscarriage, complicated delivery and delivery by caesarean section, including complicated one. This is due to endometrial functional failure, deformation of the uterine cavity, impaired contractility and shift of steroid hormone balance towards estrogens, including in the local uterine blood flow. The findings have made a significant contribution to the further development of effective strategies for the prevention and treatment of infertility in women with fibrotic uterine lesions.

\section{Conflict of interest}

The authors declare that they have no conflicts of interest. 


\section{References}

[1] Carranza-Mamane, B., Havelock, J., Hemmings, R., Cheung, A., Sierra, S., Carranza-Mamane, B. et. al. (2015). The Management of Uterine Fibroids in Women With Otherwise Unexplained Infertility. Journal of Obstetrics and Gynaecology Canada, 37 (3), 277-285. doi: http://doi.org/10.1016/s1701-2163(15)30318-2

[2] Salman, T., Davis, C. (2010). Uterine fibroids, management and effect on fertility. Current Opinion in Obstetrics and Gynecology, 22 (4), 295-303. doi: http://doi.org/10.1097/gco.0b013e32833d3606

[3] Floss, K., Garcia-Rocha, G.-J., Kundu, S., von Kaisenberg, C., Hillemanns, P., Schippert, C. (2015). Fertility and Pregnancy Outcome after Myoma Enucleation by Minilaparotomy under Microsurgical Conditions in Pronounced Uterus Myomatosus. Geburtshilfe Und Frauenheilkunde, 75 (1), 56-63. doi: http://doi.org/10.1055/s-0034-1396163

[4] Guo, X. C., Segars, J. H. (2012). The Impact and Management of Fibroids for Fertility. Obstetrics and Gynecology Clinics of North America, 39 (4), 521-533. doi: http://doi.org/10.1016/j.ogc.2012.09.005

[5] Purohit, P., Vigneswaran, K. (2016). Fibroids and Infertility. Current Obstetrics and Gynecology Reports, 5 (2), $81-88$. doi: http://doi.org/10.1007/s13669-016-0162-2

[6] Katz, T. A., Yang, Q., Treviño, L. S., Walker, C. L., Al-Hendy, A. (2016). Endocrine-disrupting chemicals and uterine fibroids. Fertility and Sterility, 106 (4), 967-977. doi: http://doi.org/10.1016/j.fertnstert.2016.08.023

[7] Dueholm, M., Lundorf, E., Hansen, E. S., Ledertoug, S., Olesen, F. (2001). Evaluation of the uterine cavity with magnetic resonance imaging, transvaginal sonography, hysterosonographic examination, and diagnostic hysteroscopy. Fertility and Sterility, 76 (2), 350-357. doi: http://doi.org/10.1016/s0015-0282(01)01900-8

[8] Cook, H., Ezzati, M., Segars, J. H., McCarthy, D. (2010). The impact of uterine leiomyomas on reproductive outcomes. Minerva ginecologica, 62 (3), 225-236.

[9] Pritts, E. A., Parker, W. H., Olive, D. L. (2009). Fibroids and infertility: an updated systematic review of the evidence. Fertility and Sterility, 91 (4), 1215-1223. doi: http://doi.org/10.1016/j.fertnstert.2008.01.051

[10] Segars, J. H. (2014). Uterine Fibroid Research. Reproductive Sciences, 21 (9), 1065-1066. doi: http://doi.org/10.1177/ 1933719114546644

[11] Segars, J. H., Akopians, A. L. (2013). The two health disparities of uterine fibroids. Fertility and Sterility, 99 (7), $1851-1852$. doi: http://doi.org/10.1016/j.fertnstert.2013.03.002

[12] Fornazari, V. A. V., Salazar, G. M. M., Vayego, S. A., Nunes, T. F., Goncalves, B., Szejnfeld, J. et. al. (2019). Impact of uterine contractility on quality of life of women undergoing uterine fibroid embolization. CVIR Endovascular, 2 (1). doi: http:// doi.org/10.1186/s42155-019-0080-2

[13] Shavell, V. I., Thakur, M., Sawant, A., Kruger, M. L., Jones, T. B., Singh, M. et. al. (2012). Adverse obstetric outcomes associated with sonographically identified large uterine fibroids. Fertility and Sterility, 97 (1), 107-110. doi: http://doi.org/10.1016/ j.fertnstert.2011.10.009

[14] Vlahos, N. F., Theodoridis, T. D., Partsinevelos, G. A. (2017). Myomas and Adenomyosis: Impact on Reproductive Outcome. BioMed Research International, 2017, 1-14. doi: http://doi.org/10.1155/2017/5926470

[15] Lisiecki, M., Paszkowski, M., Woźniak, S. (2017). Fertility impairment associated with uterine fibroids - a review of literature. Menopausal Review, 16 (4), 137-140. doi: http://doi.org/10.5114/pm.2017.72759

[16] Olive, D., Pritts, E. (2010). Fibroids and Reproduction. Seminars in Reproductive Medicine, 28 (3), 218-227. doi:10.1055/ s-0030-1251478

[17] Klatsky, P. C., Tran, N. D., Caughey, A. B., Fujimoto, V. Y. (2008). Fibroids and reproductive outcomes: a systematic literature review from conception to delivery. American Journal of Obstetrics and Gynecology, 198 (4), 357-366. doi: http://doi.org/ 10.1016/j.ajog.2007.12.039

[18] Sunkara, S. K., Khairy, M., El-Toukhy, T., Khalaf, Y., Coomarasamy, A. (2009). The effect of intramural fibroids without uterine cavity involvement on the outcome of IVF treatment: a systematic review and meta-analysis. Human Reproduction, 25 (2), 418-429. doi: http://doi.org/10.1093/humrep/dep396

[19] De Vivo, A., Mancuso, A., Giacobbe, A., Maggio Savasta, L., De Dominici, R., Dugo, N. et. al. (2011). Uterine myomas during pregnancy: a longitudinal sonographic study. Ultrasound in Obstetrics \& Gynecology, 37 (3), 361-365. doi: http://doi.org/ 10.1002/uog.8826

[20] Laughlin, S. K., Hartmann, K. E., Baird, D. D. (2011). Postpartum factors and natural fibroid regression. American Journal of Obstetrics and Gynecology, 204 (6), 496.e1-496.e6. doi: http://doi.org/10.1016/j.ajog.2011.02.018 